\title{
UNIDADES FRASEOLÓGICAS ESPECIALIZADAS: ESTADO DA QUESTÃO EM RELAÇÃO A SUA DEFINIÇÃO, DENOMINAÇÃO E CRITÉRIOS DE SELEÇÃO
}

\section{Cleci Regina Bevilacqua*}

\begin{abstract}
RESUMO: Sabe-se que a Fraseologia Especializada e seu objeto de estudo, as Unidades Fraseológicas Especializadas, vêm merecendo maior atenção a partir dos anos 90 . Desde então, observa-se um crescimento considerável de congressos e publicações dedicados ao tema. Conseqüentemente, constata-se também uma grande diversidade a respeito de sua denominação, definição e critérios para seu reconhecimento. Tal diversidade justifica-se, pelo menos em parte, em função das diferentes perspectivas a partir das quais essas Unidades são tratadas. Basicamente é possível identificar duas grandes perspectivas: uma de caráter mais lexicológico e outra de caráter mais terminológico. A partir destas constatações, neste trabalho pretendemos expor, em primeiro lugar, um panorama ou estado da questão que reflita a diversidade denominativa e conceitual das Unidades. Em segundo lugar, apresentaremos os critérios aplicados para seu reconhecimento e, finalmente, avaliaremos esses critérios, levando em conta a perspectiva da Terminologia, âmbito no qual inserimos o estudo da Fraseologia Especializada. Pretendemos, assim, expor um panorama amplo sobre algumas das questões fundamentais referentes às Unidades Fraseológicas Especializadas.
\end{abstract}

UNITERMOS: unidades fraseológicas especializadas; fraseologia especializada; Terminologia.

* Instituto de Letras da UFRGS, pesquisadora do Projeto Termisul. 
RESUMEN: La Fraseología Especializada y su objeto de estudio, las Unidades Fraseológicas Especializadas, vienen recibiendo una mayor atención desde los años 90. Se observa, desde entonces, un crecimiento significativo en el número de congresos y publicaciones dedicados a este tema. En consecuencia, se constata también una gran diversidad respecto de su denominación, definición y criterios para su reconocimiento. Esta diversidad puede justificarse, en parte, por las distintas perspectivas desde las que se tratan dichas unidades. Es posible identificar, básicamente, dos grandes perspectivas: una de carácter lexicológico y otra de carácter terminológico. A partir de estas constataciones, en este trabajo pretendemos exponer, en un primer momento, un panorama o estado de la cuestión que refleje su diversidad denominativa y conceptual. En un segundo momento, presentaremos los criterios aplicados para su reconocimiento $y$, finalmente, evaluaremos estos criterios, considerando la perspectiva de la Terminología, ámbito en el que incluimos el estudio de la Fraseología Especializada. De este modo, buscamos presentar un panorama amplio respecto de algunas cuestiones fundamentales referentes a las Unidades Fraseológicas Especializadas.

PALABRAS CLAVE: unidades fraseológicas especializadas; fraseología especializada; Terminología.

Em razão do interesse crescente pelo estudo da fraseologia especializada ${ }^{1}$ e de seu objeto de estudo, as Unidades Fraseológicas Especializadas (UFE), ${ }^{2}$ a partir dos anos 90, observa-

1 Neste trabalho, trataremos apenas a fraseologia especializada e, portanto, não faremos referência à fraseologia da lingua comum, cujos estudos estão amplamente desenvolvidos e sobre a qual há uma extensa bibliografia. Destacamos entre os estudiosos da fraseologia da língua comum Ruiz Gurillo (1997) por realizar um estudo amplo e profundo sobre o tema.

2 Veremos, ao tratar da variação denominativa referente a essas unidades, que outros autores utilizam diferentes denominações (colocação, fraseo- 
mos que coexistem diferentes perspectivas em relação a sua definição, denominação e critérios para o seu reconhecimento. A partir dessa constatação e considerando a importância que esse tema vem adquirindo, principalmente no âmbito da Terminologia, neste trabalho, pretendemos apresentar um breve estado da questão referente à fraseologia especializada e, mais especificamente, sobre as UFE. Para tanto, apresentaremos, inicialmente, a diversidade denominativa e conceitual existente em relação a essas Unidades; em seguida, revisaremos os critérios para seu reconhecimento e, finalmente, faremos uma avaliação da eficácia da aplicação desses critérios. ${ }^{3}$

Pretendemos, portanto, apresentar uma visão que busque responder as seguintes perguntas:

1) Que unidades são consideradas como Unidades Fraseológicas Especializadas?

2) Quais são as denominações que recebem essas Unidades?

3) Que critérios são utilizados para identificá-las?

Em relação à primeira pergunta, promovemos a revisão das definições propostas para as UFE (Bevilacqua, 1999). Foi possivel, então, identificar duas grandes perspectivas a partir das quais essas unidades são definidas, o que determina também os critérios utilizados para reconhecê-las.

A primeira perspectiva é lexicológica e lexicográfica, pois as define e reconhece levando em conta as propostas feitas para a fraseologia da língua comum, principalmente em autores como Hausmann (1990), Benson, Benson e Ilson (1996) e Mel'cuk (1984, 1988, 1992).

Nessa perspectiva, as unidades fraseológicas são denominadas colocações e estão formadas, basicamente, por dois elementos: um considerado a "base" e o outro, o "colocado" ou o

logismo, etc.). Apesar disso, adotamos o termo Unidade Fraseológica Especializada, tal como explicamos na continuação deste trabalho.

3 As informações aqui apresentadas são resultantes da pesquisa feita para a tese de doutorado, defendida no Instituto Universitário de Lingüistica Aplicada, da Universidade Pompeu Fabra, Barcelona, em 11 de junho de 2004. 
"elemento co-ocorrente". A base é um elemento semanticamente autônomo, ao passo que o co-ocorrente é restringido semanticamente pela base. Considera-se, também, que ambos são unidades semi-lexicalizadas e que possuem um valor semi-composicional; ou seja, que seu significado não pode ser deduzido de forma independente por cada um dos elementos que a compõem, mas pelo conjunto desses elementos. Por essas razões, os autores que seguem tal proposta afirmam que as Unidades devem ser incluídas nos dicionários e que, além disso, são memorizadas pelos falantes.

Esses autores propõem ainda determinadas estruturas morfossintáticas que auxiliam no reconhecimento das Unidades, tais como: substantivo + substantivo; substantivo + adjetivo; verbo + substantivo; adjetivo + advérbio verbo + advérbio. Alguns exemplos dessas estruturas são: fractal complexo, cometer um crime ambiental, ambientalmente nocivo.

Nessa linha de análise, encontra-se, porém, uma abordagem diferenciada.Trata-se da proposta de Mel'cuk, baseada na tipologia de relações semânticas estabelecidas entre os elementos que constituem a Unidade Fraseológica, principalmente em funções léxicas. Desse modo, para uma determinada unidade léxica atribui-se uma função que possuideterminado valor, podendo expressar-se através da fórmula:

$\mathrm{f}(X)=Y$, onde

$f$ é a função léxica

$X$ é o seu argumento (pode ser um lexema ou uma locução)

$Y$ é o valor da função

Por exemplo: a unidade ruido infernal pode ser explicada pela existência da função Magn, que é a função léxica indicativa de intensidade, grau elevado, cujo valor é indicado por infernale que se aplica ao lexema ruído. Sua representação, segundo a proposta, é: Magn (ruído) = infernal.

Finalmente, a proposta de Benson, Benson e Ilson baseiase principalmente no grau de fixação das Unidades e em determinadas estruturas morfossintáticas, semelhantes às propostas por Hausmann (substantivo + substantivo; substantivo + adjetivo; verbo + substantivo; adjetivo + advérbio; verbo + advérbio; substantivo + preposição + substantivo). 
Entre os autores que seguem essas propostas, podemos incluir Heid (1992, 1994), Martin (1992), Lainé, Pavel e Boileau (1992), L'Homme (1995, 1998), Desmet (1996) e Bejoint e Thoiron (1992). Esses autores propõem que as UFE são combinações sintagmáticas determinadas, principalmente, pela relação semântica que se estabelece entre seus elementos, por suas estruturas morfossintáticas e pela freqüência, tal como podemos ver na definição proposta por Beijoint e Thoiron (1992, p. 517):

a asociation privilégiées de quelques mots (ou termes) reliés para une estructure syntaxique et dont lês affinités syntagmatiques se concrétissent par une certaine récurrence en discours. ${ }^{4}$

A segunda perspectiva de tratamento da fraseologia especializada é de caráter terminológico. Por essa perspectiva, considera-se que as UFE são unidades sintagmáticas, formadas por dois ou mais elementos, sendo que um dos elementos que as compõem é um "termo", a partir do qual se identifica ou seleciona a Unidade. A definição proposta por Blais (1993, p. 52) reflete bem essa visão:

combinasion d'éléments linguistiques propre à un domine de spécialité, dont l'un est un terme noyau, qui son liés sémantiquement et syntaxiquement et pour lesquels il existe une contrainte paradigmatique. ${ }^{5}$

Entre os autores que seguem tal perspectiva, alguns (Pavel, 1993; Blais, 1993) estabelecem padrões morfossintáticos para as Unidades, mas não os consideram como ponto de partida

\footnotetext{
4 “Associações privilegiadas de palavras (ou termos) relacionadas por uma estrutura sintática e cujas afinidades semânticas se concretizam por certa recorrência no discurso".

5 "Combinação de elementos lingüísticos própria de um âmbito de especialidade, em que um deles é um termo núcleo, sendo que esses elementos são relacionados semântica e sintaticamente e para os quais existe uma restrição paradigmática."
} 
para seu reconhecimento, posto que, como afirmamos anteriormente, este sempre será um termo. Entre os padrões morfossintáticos identificados, podemos citar: termo + adjetivo (águas subterrâneas); verbo + termo (absorver energia); termo + verbo (os raios solares se refletem); substantivo + preposição + artigo + termo (contaminação do meio ambiente); etc.

Ainda nessa perspectiva, há autores que consideram que as Unidades Fraseológicas são de base verbal, distinguindo-as, portanto, dos "termos" os quais são, mais freqüentemente, de base nominal. Entre esses autores podemos incluir Cabré, Lorente e Estopà (1996) e Lorente, Estopà e Bevilacqua (1998).

Além de Unidades Fraseológicas consideradas como sintagmas, encontramos autores (Gouadec, 1994, Pesant e Thibault, 1993, Roberts, 1993) que propõem a inclusão de unidades maiores, equivalentes a frases inteiras. Como exemplo dessas unidades podemos citar: "esta lei entra em vigor na data de sua publicação"; "declaramos, para os devidos fins, que..."; "acusamos recebimento de seu ofício...".

Conforme afirmamos anteriormente, podemos constatar que há diferentes propostas de definições para UFE. Abaixo, apresentamos, de forma resumida, essas definições:

1) UFE como colocação; ou seja, como uma unidade resultante da combinação de duas unidades léxicas, uma das quais é o núcleo (colocador) e a outra o colocado; são semilexicalizadas e possuem determinados padrões morfossintáticos;

2) UFE como combinação sintagmática, que tem como núcleo central um termo ou uma unidade terminológica (UT), a partir da qual se identifica a unidade;

3) UFE como unidades maiores, que podem ser frases próprias de determinado âmbito do conhecimento.

Além de identificar essa diversidade conceitual em relação às UFE, observamos que as diferentes definições podem relacionar-se diretamente à delimitação dessas unidades. Assim, observamos que, dependendo da definição de UFE que se adota, seus limites serão diferenciados, sendo possível, aliás, identificar duas grandes tendências de estudo. 
Essa delimitação refere-se principalmente às unidades de base nominal, pois é em relação a elas que se gera a discussão sobre os limites entre unidades terminológicas sintagmáticas e unidades fraseológicas. ${ }^{6}$ Para exemplificar essa discussão, tomamos o exemplo da Unidade apresentada anteriormente: fractal complexo. Para alguns autores (Heid, Martin, etc.) essa construção será uma unidade fraseológica, pois consideram fraseológicas todas as unidades superiores a uma unidade léxica simples. Ao contrário, para outros autores (Blais, Lorente, Bevilacqua e Estopa) essas unidades são terminológicas e não fraseológicas.

Assim, a primeira perspectiva em relação a essa discussão, baseia-se, fundamentalmente, na visão lexicológica de UFE, considerando todo sintagma ou unidade complexa como fraseológica. É o caso do exemplo mencionado (fractal complexo), ou ainda de posologia prudente considerados unidades fraseológicas ou colocações. Portanto, trata-se de uma perspectiva ampla de unidade fraseológica, dado que nela estão incluídas desde unidades complexas ou sintagmas formados por duas unidades lexicais até frases completas.

Contrapondo-se a essa concepção mais ampla, encontramos uma perspectiva, de caráter mais terminológico, que considera necessário estabelecer a diferença ou o limite entre os sintagmas ou unidades complexas de base nominal, pois essas podem caracterizar-se como termos (fractal complexo, posologia prudente) que se distinguem de unidades como iniciar / inicializar um programa; salvar um arquivo ou esta lei entra em vigor na data de sua publicação.

6 Acreditamos que os limites entre as unidades terminológicas sintagmáticas de caráter nominal e as fraseológicas constituem-se um tema de estudo importante, principalmente para aqueles que se dedicam à elaboração de produtos terminográficos, pois tem conseqüências na seleção das entradas. Por exemplo, "contaminação" é um termo do meio ambiente, mas "contaminação do meio ambiente" pode ser uma fraseologia. Na tese de doutorado, estabelecemos alguns testes que permitem identificar: a) quando uma unidade é terminológica, caracterizando-se como uma nominalização resultativa, e b) quando uma unidade é fraseológica, caracterizando-se como uma nominalização eventiva. Para mais detalhes, ver Bevilacqua, 2004, cap. 8. 
Entre os argumentos utilizados para sustentar a diferença entre os sintagmas de base nominal, considerados como termos, e os sintagmas considerados como fraseológicos estão os seguintes:

a) sintáticos: os "termos" são de categoria nominal, ao passo que as UFE são mais freqüentemente de categoria verbal, embora também possam ser adjetivais ou, inclusive, preposicionais, conforme afirmamos anteriormente;

b) semânticos: os "termos" são definidos como unidades léxicas de caráter denominativo, referindo-se a um conceito, ao passo que as UFE são de caráter relacional e não se referem a um único conceito, mas são resultantes da combinação de conceitos (Blais, 1993).

Após a revisão desses autores e situando-nos na perspectiva terminológica da fraseologia, elaboramos uma definição de UFE que apresentamos abaixo: ${ }^{7}$

São unidades formadas por um núcleo eventivo, considerado como tal por ser de base verbal ou derivada de verbo (nominalização ou particípio), e por um núcleo terminológico (termo). Entre estes dois núcleos se estabelecem relações sintáticas, mas principalmente semânticas, determinadas pelas propriedades do texto em que são utilizadas. Portanto, são unidades que se conformam no e pelo texto em que são utilizadas. Cumprem, tal como os termos, a função de representar e transmitir conhecimento especializado.

Citamos, como exemplos, algumas unidades referentes ao âmbito da energia solar: captar radiação, captação de radiação, absorver energia, absorção de energia. Nesses exemplos, captar, captação, absorver e absorção são os "núcleos eventivos", enquanto radiação e energia são os "núcleos terminológicos".

7 Essa definição foi elaborada considerando também a análise dos dados coletados para a tese de doutoramento. 
Pela definição que construímos, consideramos importante estabelecer a distinção entre sintagmas terminológicos e UFEs. Desse modo, além das propriedades acima mencionadas para as UFE, podemos dizer que são elas de caráter mais relacional, ao passo que as unidades terminológicas têm caráter denominativo e valor referencial, representando um núcleo ou nó de conhecimento em determinado âmbito. Para simplificar essas afirmações, podemos retomar o que já indicamos anteriormente: as unidades terminológicas referem-se a um conceito, ao passo que as UFEs representam a união de conceitos.

Enfim, com a apresentação desse conjunto de informações, respondemos a primeira pergunta (Que unidades são consideradas como unidades fraseológicas especializadas?), chamando a atenção para as diferentes definições propostas para essas Unidades, determinadas por perspectivas de análise também distintas. Portanto, para os interessados em estudar o assunto, salientamos que é fundamental conhecer, antes, a existência dessa diversidade para, então, definir os caminhos que se deseja seguir.

Além desta diversidade conceitual, conforme afirmamos anteriormente, também é possivel identificar a existência de uma diversidade denominativa; isto é, os autores e estudiosos das UFE utilizam diferentes denominações para referir-se a um mesmo objeto de estudo. Assim, podemos encontrar as seguintes denominações para o que chamamos de Unidades Fraseológicas Especializadas:

- colocação (Heid, 1992, 1994; Martin, 1992; Desmet, 19951996);

- colocação das linguagens especializadas (L'Homme, 1998, 2000);

- co-ocorrente (Lainé, Pavel, Boileau, 1992; Pesant e Thibault, 1993);

- entidade fraseológica (Gouadec, 1994);

- frasema (Gréciano, 1993);

- fraseologismo (Blais, 1993; Pavel, 1993);

- unidade fraseológica (Gouadec, 1994);

- unidade fraseológica especializada (Cabré, Lorente e Estopà, 1996; Bevilacqua, 2004) . 
Embora exista essa diversidade denominativa, ressaltamos que ela nem sempre implica uma diversidade conceitual, uma vez que, cada uma dessas denominações nem sempre corresponde a uma concepção ou definição necessariamente diferenciada de UFE dentro das perspectivas mencionadas anteriormente. Isso significa dizer que um mesmo autor que considere, por exemplo, as UFEs como sintagmas formados por determinadas estruturas morfossintáticas (substantitvo + substantitvo; substantitvo + adjetivo, etc.) pode nomeá-las de diferentes formas (fraseologismo, colocação, etc.).

Deste modo, para responder a segunda pergunta feita no início deste trabalho -(Quais são as denominações que recebem estas unidades?), teremos de fazer referência à diversidade denominativa. Contudo, apesar dessa diversidade, é possivel observar que as denominações de uso mais freqüente são: fraseologismo, unidade fraseológica especializada, colocação, colocação especializada. Considerando essas diversas possibilidades, optamos pela denominação Unidade Fraseológica Especializada, por considerar que esta reflete de forma mais adequada a definição que para elas estabelecemos.

Depois dessa breve revisão em relação às definições e denominações existentes sobre as UFEs, apresentaremos os elementos que permitem responder a terceira pergunta deste trabalho: Que critérios são utilizados para identificá-las?

A revisão bibliográfica dos principais autores que se dedicam ao tema da fraseologia, a maioria dos quais já mencionada neste trabalho, permite-nos chegar aos seguintes critérios aplicados para o reconhecimento das UFEs.

a) Caráter sintagmático: é uma condição intrínseca dessas Unidades, pois para ser considerada fraseológica, a Unidade deve ser sintagmática, isto é, deve ser uma Unidade formada por mais de uma unidade léxica.

b) Estabilidade semântica: a maioria dos autores, embora nem sempre de forma explícita, relaciona essa estabilidade com a possibilidade de comutação de algum dos elementos que compõe a Unidade, e estabelecem graus diferenciados de fixação, conforme as possibilidades 
combinatórias mais ou menos amplas. Assim, determinado termo pode combinar-se com um, alguns poucos ou vários elementos. Por exemplo, uma unidade de grau de fixação elevado pode ser os raios solares incidem (incidir os raios solares), e unidades semifixas podem ser aumentar a temperatura ou elevar a temperatura.

c) Estabilidade sintática: refere-se à identificação das UFEs a partir de determinados padrões morfossintáticos préestabelecidos, conforme os citados anteriormente $(\mathrm{V}+\mathrm{N}$, $\mathrm{N}+$ Adj., etc.), e também à possibilidade de inserção de elementos lingüísticos no interior da unidade.

d) Grau de fixação: propriedade determinada pelos itens b e c;

e) Inclusão de, no mínimo, um termo ou unidade terminológica: conforme apontamos anteriormente, para alguns autores esse é o ponto de partida para a identificação das UFEs, uma vez que o termo é considerado o núcleo que confere valor especializado à Unidade e a partir do qual se reconhece a Unidade;

f) Semi-composicionalidade ou composicionalidade das UFE: por "semi-composicionalidade" entende-se que um dos elementos da Unidade, geralmente o co-ocorrente do termo, adquire um sentido novo. Por exemplo, máscara, na combinação máscara de oxigênio. Já na "composicionalidade" cada elemento mantém o seu sentido, e o significado da unidade é dado por cada um dos elementos (por exemplo, aumentar a temperatura).

g) Uso em âmbito específico: determina que uma Unidade é própria de um campo de conhecimento e, de acordo com algumas propostas, é isso que determina sua prototipicidade, tal como ocorre no discurso jurídico ou administrativo ("sancionar a lei", "nos termos do parágrafo...", "sendo o que tínhamos para o momento, despedimo-nos").

h) Freqüência relevante: esse critério determina que uma UFE deve ter uso recorrente nos textos de determinada área ou temática.

Observamos que alguns desses critérios são obrigatórios e outros, facultativos, dependendo da tendência que se siga em re- 
lação à concepção de fraseologia. Assim, para alguns, o critério de semicomposicionalidade ou composicionalidade não é relevante, enquanto que para outros esse fator será importante para o reconhecimento das UFE, principalmente para aqueles que seguem a tendência lexicológica. Apesar dessa constatação, podemos observar que há um consenso em relação aos critérios seguintes:

a) presença de uma unidade terminológica;

b) estabilidade sintática;

c) estabilidade semântica;

d) índice de freqüência relevante;

e) uso em determinado campo especializado.

Sobre esses critérios teceremos alguns comentários a partir da coleta de dados realizada para a tese de doutorado ${ }^{8}$ os quais nos permitiu fazer uma avaliação da eficácia de sua aplicação no reconhecimento das UFEs.

Em primeiro lugar, podemos constatar que a conformação das UFEs como unidades sintagmáticas é um critério intrínseco, pois faz parte da natureza da UFE estar formada por mais de um elemento lingüístico. No entanto, consideramos importante ressaltar que esse critério, embora obrigatório, não é exclusivo das unidades fraseológicas, pois pode caracterizar também as unidades terminológicas sintagmáticas, tais como selo verde, energia eólica ou energia do vento, ou ainda unidades livres, como apostar pela energia. Portanto, é um critério pouco distintivo para caracterizar as UFEs.

Em segundo lugar, observamos que o critério de fixação alta ou relativamente alta implica, geralmente, não apenas os crité-

8 A seleção das UFEs que formam o corpus de análise da tese foram coletadas utilizando-se a ferramenta Bwana, que permite extrair informações do corpus do Instituto Universitário de Lingüística Aplicada (IULA). Para realizar a coleta, foram realizadas buscas a partir de determinados núcleos eventivos coletados em trabalho de pesquisa anterior à tese (Bevilacqua, 1999). Considerando a definição de UFE proposta e os critérios para sua identificação, foi possivel identificar as UFEs específicas no âmbito do aproveitamento da energia solar, temática do corpus da tese. 
rios sintáticos, mas também os semânticos (por exemplo, a substituição de elementos no interior da unidade; seu valor de termo em determinada área do conhecimento). Freqüentemente, essa estabilidade é medida pela possibilidade de comutação e inserção dos elementos no interior da Unidade, parâmetros que podem ser adequados, mas que não são suficientes para explicar a estabilidade das UFEs ou, mais que isso, a relação semântica entre os elementos que as conformam. Além disso, deve-se considerar que essas unidades possuem grande variação de estruturas morfossintáticas. Por exemplo, pode-se encontrar absorver calor, absorver o calor, absorver mais calor, absorver muito calor, etc.

Tal variedade de estruturas pode levar a pensar que cada uma dessas unidades é distinta, é única, e que se deveria estabelecer as estruturas morfossintáticas para cada uma delas, assim como a sua freqüência.

No entanto, considerando a definição de UFE que estabelecemos, acreditamos que a fixação das UFEs é determinada pelos dois grandes núcleos que a compõem: o núcleo eventivo, verbal ou derivado de verbo (por exemplo: captar, absorver, captação, absorção), e o núcleo terminológico (energia, calor, radiação). Além disso, se partimos desses dois núcleos, identificaremos as demais estruturas morfossintáticas possiveis. Desse modo, se temos uma unidade formada pelo núcleo eventivo captar e pelo núcleo terminológico calor, é possivvel identificar e organizar, a partir dela, as demais estruturas, tal como vemos a seguir:

$$
\begin{aligned}
& \text { [captar calor] - verbo + termo: } \\
& \text { captar o calor - verbo + artigo + termo } \\
& \text { captar mais calor - verbo + advérbio + termo } \\
& \text { captar este calor - verbo + pronome + termo }
\end{aligned}
$$

Assim, considerando que a UFE está formada por dois núcleos centrais, é possivel agrupar todas as unidades formadas pelos mesmos núcleos e, inclusive, identificar a freqüência não para cada estrutura morfossintática, mas para o conjunto de unidades formadas pelos mesmos núcleos. Aos exemplos apresentados anteriormente, somaríamos uma freqüência total de quatro ocorrências e não a freqüência um para cada uma das estruturas morfossintáticas. 
Em terceiro lugar, podemos constatar que a identificação das UFEs por determinados padrões morfossintáticos gera muito ruído e também silêncio. Ou seja, obtivemos como resultado unidades que não são fraseológicas, por um lado, e por outro, deixamos de recolher outras que o são.

Em quarto lugar, para o reconhecimento das UFEs, consideramos que a inclusão de um termo, no mínimo, é uma condição necessária, mas não suficiente, pois há outras unidades sintagmáticas que podem incluir um termo e que não são UFEs como, por exemplo, apostar pela energia, que inclui o termo energia, mas é uma unidade livre por não cumprir a função de representar e transmitir conhecimento especializado sobre o tema.

Em quinto lugar, consideramos fundamental o uso da UFE numa área específica do conhecimento ou em textos referentes a determinadas temáticas especializadas, pois acreditamos que é por esse uso específico que as UFEs adquirem valor de unidade e também seu valor especializado. Na nossa visão, portanto, as UFEs somente se constituem como tal pelas propriedades pragmáticas dos textos (temática, emissor, receptor, objetivos) em que são utilizadas.

Finalmente, observamos que o critério de freqüência elevada também não é suficiente para identificar as possiveis UFEs. Para reconhecer essas unidades consideramos que é necessário levar em conta os dois núcleos que formam a Unidade e, a partir deles, agrupar todas as unidades formadas por eles para poder ter uma freqüência para o conjunto e não para as estruturas superficiais individuais, conforme mencionamos anteriormente. Além disso, acreditamos que é pela função de representar e transmitir conhecimento especializado que as UFEs adquirem valor de unidade, mais que por sua freqüência.

Em resumo, da revisão desse conjunto de critérios, podemos constatar que a tarefa de reconhecimento da UFE é complexa e supõe a aplicação conjunta de determinados critérios para que os mesmos sejam eficazes. Ressaltamos ainda que, nesse processo de reconhecimento, é necessário considerar as especificidades do texto ou da área em que as Unidades são utilizadas, pois são essas especificidades que ajudam a determinar o valor não só de uma unidade como fraseológica, mas também como 
unidade especializada própria de um âmbito do conhecimento ou temática.

Com esse conjunto de informações, acreditamos ter sido possivel apresentar um amplo panorama referente a alguns aspectos essenciais relacionados às UFEs, principalmente à problemática em torno de sua definição e dos critérios para seu reconhecimento. Esperamos que se constitua, portanto, num estado da questão que possa servir de base para os estudiosos interessados no tema da fraseologia especializada.

\section{Referências Bibliográficas}

BENSON, M.; BENSON, E.; ILSON, R. (1996) The BBI combinatory dictionary of English. Amsterdam: John Benjamins Publishing Company.

BÉJOINT, H.; THOIRON, Ph. (1992) Macroestructure et microstructure dans un dictionnaire de collocations en langue de spécialité. Terminologie et traduction, 2-3. Bruxelas: Comisión des Communautés Européennes, Service de Traductions, p. 513-522.

BEVILACQUA, C. R. (2004) Unidades Fraseológicas Especializadas Eventivas: descripción y reglas de formación en el ámbito de la energía solar. Tese de Doutoramento em Lingüística Aplicada. Universidade Pompeu Fabra, Instituto Universitário de Lingüística Aplicada (IULA), Barcelona.

. (1999) Unidades Fraseológicas Especializadas: estado de la cuestión y perspectivas. Trabalho de Pesquisa (Doutorado em Lingüistica Aplicada). Universidade Pompeu Fabra, Instituto Universitário de Lingüistica Aplicada, Barcelona.

BLAIS, E. (1993) La phraséologie. Une hypothèse de travail. Terminologies Nouvelles, 10. Bruxelas: RINT, p. 50-56.

CABRÉ, M. T.; LORENTE, M.; ESTOPÀ, R. (1996) Terminología y fraseología. In: Simposio de Terminología Iberoamericana, V, 1996, Ciudad de México. Anais do V Simpósio de Terminologia Iberoamericana. Ciudad de México: Riterm, Colegio de México, p. 67-81.

DESMET, I. (1996) Pour une approche terminologique des sciences sociales et humaines. Les sciences sociales et humaines du travail en portugais et en français. Tese de Doutoramento em Lingüistica Aplicada, vol. II. Universidade de Paris XIII. 
GOUADEC, D. (1994) Nature et traitement des entités phraséologiques. Terminologie et phraséologie. Acteurs et amenageurs: In: Deuxième Université d'Automne en Terminologie. Paris: Actes de la Deuxième Université d'Automne en Terminologia. La Maison du Dictionnaire, p. 167-193.

GRÉCIANO G. (1993) Vers une modélisation phrasélogique: acquis et projets d'EUROPHRAS. Terminologies Nouvelles, 10. Bruxelas: RINT, p. 16-22.

HAUSMANN, F. J. (1990) Le dictionnaire de collocations. In: HAUSMANN, F. J. et al. An International encyclopedia of lexicography. Berlin, New York: Walter de Gruyter, vol. 1, p. 1010-1019.

HEID, U. (1994) On ways words work together - topics in lexical combinatoris. In: MARTIN, W. et al. Euralex'94 Proceedings. Amsterdam, p. 226-257.

HEID, U. (1992) Décrire les collocations: deux approches lexicographiques et leur application dans un outil informatisé. Terminologie et traduction 2/3. Bruxelas: Commission des Communautés Européennes, Service de Traduction, p. 523-548.

LAINÉ, C.; PAVEL; S.; BOILEAU, M. (1992) La phrasélogie - nouvelle dimension de la recherche terminologique. Travaux du module canadien du RINT. L'Actualité terminologique, 25/3. Canadá: Bureau de Traduction, p. 5-9.

L'HOMME, M-C. (2000) Understanting Specialized Lexical Combinations. In: Terminology, vol. 6, n. 1, p. 89-110.

- (1998) Caractérisation des combinaisons lexicales spécialisées par raport aux collocations de langue générale. In: FONTENELE, T. et. al. Euralex'98 Proceedings. Liège: Université de Liège, vol. II, p. 513-522.

LORENTE, M; BEVILACQUA, C.R.; ESTOPÀ, R. (2002) El análisis de la fraseología especializada mediante elementos de la lingüística actual". In: CORREA, M (org.). Atas VI Simpósio da Rede Ibero-americana de Terminologia. Terminología, desenvolvimento e identidade nacional. Lisboa: Ed. Colibrí, p. 635-653.

MARTIN, W. (2002) Remarks on Collocations in sublanguages. In: Terminologie et traduction, 2/3. Bruxelas: Commission des Communautés Européennes, Service de Traduction, p. 157-164.

MEL'CUK, I. (1984, 1988, 1992) Dictionnaire Explicatif et combinatoire du français contemporain. Vol. 1, 2, 3. Montréal: Les Presses de la Université de Montréal. 
PAVEL, S. (1993) La phraséologie en langue de spécialité. Méthodologie de consignation dans les vocabulaires terminologiques. Terminologies Nouvelles, 10. Bruxelas: RINT, p. 67-82.

PESANT, G.; THIBAULT, E. (1998) Pour une combinatoire phraséologique de la publicité des droits. Meta: Journal des Traducteurs, 43-2. Montréal: Les Presses Universitaires de Montréal, p. 328-331. - (1993) Terminologie et cooccurrence en langue du droit. Terminologies Nouvelles, 10. Bruxelas: RINT, p. 23-35.

ROBERTS, R. (1994-1995) Identifying the phraseology of languages for special purposes (LSPs). Alfa: Actes de langue française et de linguistique. Canada, Universitas Dalhousiana, Halifax, vol. 7/8, p. 61-69. RUIZ GURILlO, L. (1997) Aspectos de fraseología teórica española.. València: Universitat de València,Cuadernos de Filología Anejo XXIV. 